JKEP

Vol 5, No 1, Mei 2020

ISSN: 2354-6042 (Print)

ISSN : 2354-6050 (Online)

\title{
Penurunan Tingkat Nyeri Bayi Saat Imunisasi Pentavalen Dengan Pemberian ASI Secara Menyusui
}

\author{
Indah Permatasari ${ }^{1}$, Ritanti $^{2}$ \\ ${ }^{1}$ Departemen Keperawatan Anak, UPN Veteran Jakarta \\ ${ }^{2}$ Departemen Keperawatan Komunitas, UPN Veteran Jakarta \\ E-mail: indahpermatasari@upnvj.ac.id
}

\author{
Artikel history \\ Dikirim, May $8^{\text {th }}, 2020$ \\ Ditinjau, May $9^{\text {th }}, 2020$ \\ Diterima, May $12^{\text {th }}, 2020$
}

\begin{abstract}
Immunization pain is a stimulus that can cause trauma and changes affective response in the baby. Breastfeeding is the alternative strategies to reduce pain response due in invasive procedures. The aims of this study is to determine the effect of breastfeeding on infant pain levels when getting pentavalent immunization. This research using Randomized Controlled Trial design unblind, post-test design, with a sample of 70 healthy infants consisted of 34 respondents intervention group and 36 respondents of the control group were selected by random block technique. Breastfeeding intervention is given from two minutes before to 2 minutes after the immunization. In this study showed the pain level of intervention group is lower than the level of pain group $(p=$ $0.000 ; \alpha=0.05)$. breast-fed infants when immunized can reduce the risk of severe pain by $80 \%$, which compared to not breastfed infants. Further research on the effect of breast feeding for preterm infants pain response in invasive procedure.
\end{abstract}

Keywords: ASI; Pentavalent immunization; Breastfeeding, pain

\begin{abstract}
ABSTRAK
Rasa nyeri saat imunisasi adalah stimulus yang menyebabkan trauma dan perubahan respon afektif pada bayi. Pemberian ASI dengan cara menyusui adalah salah satu usaha untuk meminimalkan nyeri akibat tindakan invasif. Penelitian ini untuk mengetahui pengaruh pemberian ASI dengan cara menyusui terhadap tingkat nyeri bayi saat dilakukan imunisasi pentavalen. Penelitian ini dilakukan pada awal bulan juli sampai akhir bulan agustus, diwilayah kerja salah satu puskesmas kabupaten Sleman Yogyakarta, dengan menggunakan alat ukur skala nyeri FLACC (Face, Legs, Activity, Cry and Consolability). Desain penelitian ini menggunakan rancangan Randomized Controlled Trial unblind, post-test design, dengan total sampel 70 bayi sehat yang terbagi menjadi 34 responden kelompok intervensi dan 36 responden kelompok kontrol, pemilihan sampel dilakukan dengan tehnik block random. intervesi menyusui diberikan
\end{abstract}


mulai dua menit sebelum sampai 2 menit setelah tindakan imunisasi. Hasil penelitian menunjukkan tingkat nyeri kelompok intervensi lebih rendah dibandingkan dengan tingkat nyeri kelompok kontrol $(p=0,000 ; \alpha=0,05)$, Bayi yang diberi ASI dengan cara menyusui saat diimunisasi dapat menurunkan resiko terjadinya nyeri berat (skala 7-10) sebesar $80 \%$. Penelitian lanjutan tentang pengaruh pemberian ASI dengan cara menyusui terhadap respon nyeri bayi prematur pada tindakan invasive.

Kata Kunci: ASI; Imunisasi pentavalen; Menyusui; Nyeri

\section{PENDAHULUAN}

Imunisasi pentavalen merupakan tindakan medis yang rutin dilakukan pada bayi dan menimbulkan nyeri ringan (skala 1-3), nyeri sedang (4-6), dan nyeri berat (skala 7-10) tergantung dari respon nyeri setiap individu, karena prosedur pemberiannya dilakukan secara injeksi intramuscular (Pope N., et al, 2018). Tindakan ini selain menyebabkan trauma dan rasa sakit pada bayi juga memberikan efek toxic stress yang positif dan negatif terhadap perkembangan anak selanjutnya (Sridharan K, Sivaramakrishnan G, 2018).

Menurut Bard, et al (2010) nyeri merupakan suatu stimulus yang dapat menyebabkan kerusakan perkembangan otak jika tidak ditangani dengan tepat. Dampak jangka panjang nyeri berupa gangguan konsentrasi belajar dan gangguan perilaku pada anak. Sehingga, dibutuhkan metode keperawatan yang dapat meminimalkan tingkat nyeri saat pemberian tindakan invasif seperti imunisasi (Badr, L.K, . et al, 2010).

Tingkat stres yang dialami saat tindakan invasif dapat memperburuk pengalaman nyeri bayi, hal ini dibuktikan dalam penelitian Bard, et al (2010) pada 96 bayi baru lahir yang mendapat tindakan heel lance, menunjukkan hasil adanya peningkatan persentase bayi menangis, peningkatan denyut jantung, tekanan darah dan saturasi oksigen pada saat dan setelah tindakan dilakukan. ${ }^{4}$ Alternatif tindakan keperawatan yang dapat dilakukan untuk mengurangi repon nyeri bayi saat tindakan invasif yaitu dengan pemberian ASI dengan cara menyusui.

Hasil penelitian M.Kasab et al., (2020) menjelaskan pemberian ASI dengan cara menyusui efektif mengurangi nyeri selama tindakan invasif pada bayi baru lahir. Metode pemberian ASI dengan cara menyusui bisa menjadi salah satu pilihan karena penggunaannya 
sederhana, aman, memiliki efek yang cepat, sehingga ideal untuk tindakan medis yang rutin dilakukan seperti imunisasi. ${ }^{5}$ Penelitian ini dilakukan untuk mendukung penelitian sebelumnya untuk membuktikan ASI dapat menurunkan nyeri bayi saat tindakan imunisasi.

\section{METODE}

Metode pada penelitian ini adalah $R C T$ unblind, post-test design yang membandingkan hasil perlakuan antara kelompok intervensi dengan kelompok kontrol yang keduanya mendapatkan perlakuan yang berbeda. Pada kelompok intervensi bayi disusui selama 2 menit sebelum imunisasi dimulai, kemudian setelah 2 menit menyusu baru dilakukan imunisasi pada daerah vastus lateralis, dan selama prosedur ibu tetap menyusui bayinya, sedangkan pada kelompok kontrol bayi diletakkan ditempat tidur sambil ditunggui oleh orang tua/wali bayi, kemudian dilakukan imunisasi pada daerah vastus lateralis. Populasi penelitian adalah semua bayi usia 2-6 bulan yang mendapat imunisasi Pentavalen di salah satu wilayah kerja Puskesmas di Kabupaten Sleman Yogyakarta.
Adapun kriteria inklusi sampel antara lain: bayi yang akan diimunisasi Pentavalen, berusia 2-6 bulan, menyusu ASI eksklusif atau parsial, BBL > 2.500 gram, tidak demam (suhu tubuh normal $36.5-37,2{ }^{\circ} \mathrm{C}$ untuk pengukuran suhu lewat ketiak), dan orangtua menyetujui informed consent. Kriteria eklusi sampel antara lain: bayi yang pernah dirawat inap dirumah sakit lebih dari 48 jam, bayi lahir prematur (usia kehamilan <37 minggu), bayi memiliki riwayat pembedahan/ operasi sebelumnya, dan bayi yang tetap menangis walaupun sudah ditenangkan menjelang di imunisasi.

Total sampel dalam penelitian ini 70 bayi (34 kelompok perlakuan, dan 36 kelompok kontrol) pemilihan sampel dengan tehnik block random. Waktu penelitian mulai Juli-Agustus 2015 setelah mendapat izin Komite Etik Fakultas Kedokteran Universitas Gadjah Mada dengan nomor surat Ref: KE/FK/889/EC/2015. Instrumen Penelitian menggunakan FLACC untuk mendapat data tingkat nyeri bayi, lembar skrining untuk menilai kriteria inklusi dan eklusi sampel serta data karakteristik responden, dan lembar observasi perlekatan posisi menyusui. 
Penilaian skala nyeri FLACC dilakukan mulai dari "in" jarum disuntikkan ke bayi sampai kurang dari 1 menit pertama setelah "out" jarum dicabut dari paha bayi. Penentuan nilai nyeri berdasarkan skala FLACC dilakukan oleh 2 orang ners yang berpengalaman dalam menilai tingkat nyeri anak di salah satu bangsal anak rumah sakit pemerintah di Semarang. Penilaian dilakukan dengan melihat hasil rekaman video secara berulang-ulang, cermat dan teliti, tanpa mengetahui hipotesis dan tujuan dari dilakukannya penilaian tersebut. Data dianalisis menggunakan analisis univariat dan bivariat, yang sebelumnya telah dilakukan uji normalitas (uji Kolmogorov-Smirnov) dan uji homogenitas (dengan melihat nilai levene statistic). Untuk analisis data bivariat digunakan analisis uji statistik Chi-square.

\section{HASIL DAN PEMBAHASAN}

Rata-rata responden memiliki umur dan pengalaman imunisasi sebelumnya $\geq 3$ pada kelompok intervensi $(2,7647$, $\mathrm{SD}=0,81868$ ) dan kelompok kontrol $(2,9722, \quad \mathrm{SD}=0,81015) . \quad$ Sedangkan untuk jenis kelamin pada kelompok intervensi didominasi oleh perempuan $(67,6 \%)$, sedangkan pada kelompok kontrol didominasi oleh laki-laki $(69,4 \%)$. Untuk tingkat nyeri pada kelompok intervensi sebagian besar responden berada pada nyeri ringannyeri sedang sebanyak $79,4 \%(5,0882$, $\mathrm{SD}=1,63980$ ), sedangkan tingkat nyeri responden pada kelompok kontrol $100 \%$ berada pada nyeri berat $(5,0882$, $\mathrm{SD}=1,63980$ ). Hasil uji homogenitas menunjukkan bahwa varians data karakteristik responden pada kedua kelompok adalah setara $(\mathrm{p}>0,05)$

Tabel 1. Karakteristik responden Berdasarkan Kelompok Kontrol dan Kelompok Intervensi

\begin{tabular}{lccc}
\hline \multicolumn{1}{c}{ Variabel } & $\begin{array}{c}\text { Kelompok Kontrol } \\
(\mathbf{n = 3 6})\end{array}$ & $\begin{array}{c}\text { Kelompok Intervensi } \\
(\mathbf{n = 3 4})\end{array}$ & $\begin{array}{c}\boldsymbol{p} \\
\text { value }\end{array}$ \\
& $\begin{array}{c}\text { Mean(SD) } \\
\text { Mean(SD) }\end{array}$ & \\
$\begin{array}{l}\text { Umur (bulan) } \\
\text { Pengalaman }\end{array}$ & $2,9722(0,81015)$ & $2,7647(0,81868)$ & 0,485 \\
$\begin{array}{l}\text { imunisasi } \\
\text { sebelumnya (kali) }\end{array}$ & $2,9722(0,81015)$ & $2,7647(0,81868)$ & 0,485 \\
$\begin{array}{l}\text { Jenis kelamin } \\
\text { (laki- }\end{array}$ & & & \\
laki/perempuan) & $25 / 11$ & $11 / 23$ & 0,751 \\
\hline
\end{tabular}


Hasil penelitian menunjukkan bahwa umur tidak memberikan pengaruh yang bermakna terhadap tingkat nyeri bayi saat dilakukan imunisasi dengan $\mathrm{p}=$ $0,270$ ( $>00,05)$. Dalam penelitian ini umur responden berada pada rentang yang sama yaitu 2-4 bulan pada seluruh kelompok. Umur 2-4 bulan termasuk dalam kategori bayi muda, dan memiliki reaksi yang sama terhadap respon nyeri. Bayi muda belum dapat mengucapkan secara verbal rasa nyeri yang dialami, beranjak dari hal ini diperlukan pendekatan lain untuk mengkaji tingkat nyeri yang dirasakan anak (termasuk mengobservasi perubahan perilaku dan ekspresi anak) (Carbajal R., et al, 2003).

Hasil analisis variabel jenis kelamin dalam penelitian menggambarkan tidak adanya hubungan jenis kelamin dengan respon nyeri saat diimunisasi $\mathrm{p}=0,056$ (p> 0,05). Hal ini berbeda dengan pendapat McGrath \& Hillier (2003) dalam Oakes (2011) yang menjelaskan pengaruh jenis kelamin terhadap respon nyeri masih belum jelas. Pendapat serupa dikemukakan oleh Potter dan Perry (2009) dalam Schechter (2007) bahwa jenis kelamin dapat mempengaruhi nyeri, pada laki-laki ambang batas respon nyeri lebih tinggi dibandingkan dengan pada perempuan. Namun kedua pendapat tersebut bertolak belakang dari hasil penelitian ini, dimana tidak ditemukan perbedaan respon nyeri yang ditunjukkan selama observasi penelitian antara responden laki-laki dan perempuan (Sanz-rojo S, Garicano-vilar E, 2016).

Pengalaman imunisasi sebelumnya pada responden dihitung berdasarkan berapa kali responden pernah menjalani injeksi imunisasi sebelum pemberian injeksi imunisasi saat kunjungan penelitian. Hasil penelitian menyebutkan tidak ada hubungan bermakna antara pengalaman imunisasi sebelumnya terhadap tingkat nyeri bayi saat diimunisasi, dan jumlah pengalaman imunisasi minimal sebanyak 2 kali, dan pengalaman imunisasi maksimal sebanyak 4 kali.

Memori nyeri yang pernah didapat tidak selamanya membantu dalam menghadapi nyeri-nyeri selanjutnya. Apabila individu sering mengalami memori buruk terhadap nyeri dan menimbulkan kecemasan serta rasa takut berlebih makan hal ini akan memperburuk kondisi nyarinya. Berbanding terbalik dengan individu yang mempu melewati respon nyeri 
dengan baik atau dapat diatasi, maka akan lebih baik bagi individu tersebut dalam mempersepsikan nyeri
(Schechter NL, et al 2007 \& Potter PA, Perry AG, 2005).

\section{Tabel 2. Pengaruh Karakteristik Responden Terhadap Tingkat Nyeri Saat Imunisasi}

\begin{tabular}{llccc}
\hline \multicolumn{1}{c}{ Karakteristik } & $\begin{array}{c}\text { Nyeri ringan- } \\
\text { nyeri sedang }\end{array}$ & $\begin{array}{c}\text { Tingkat Nyeri } \\
\text { Nyeri berat }\end{array}$ & P value \\
Umur & $\geq 3$ bulan & $14(33,3 \%)$ & $28(66,7 \%)$ & 0,270 \\
Pengalaman & $\geq 3$ bulan & $13(46,4 \%)$ & $15(53,6 \%)$ & \\
imunisasi & $<3$ kali & $14(33,3 \%)$ & $28(66,7 \%)$ & 0,270 \\
Jenis kelamin & $13(46,4 \%)$ & $15(53,6 \%)$ & \multirow{2}{*}{ Laki-laki } \\
& Perempuan & $10(27,8 \%)$ & $26(72,7 \%)$ & 0,056 \\
& $17(50,0 \%)$ & $17(50,0 \%)$ & \\
\hline
\end{tabular}

Tabel 3 menunjukkan adanya perbedaan antara tingkat nyeri bayi saat dilakukan tindakan invasif antara kelompok kontrol dan kelompok intervensi $(\mathrm{p}=0,000)$. Perbedaan tersebut menunjukkan adanya pengaruh pemberian ASI dengan cara menyusui dalam mengurangi tingkat nyeri bayi saat imunisasi pentavalen. Hasil lainnya menunjukkan bahwa kelompok yang diberi ASI dengan cara menyusui saat diimunisasi memiliki kemungkinan 0,206 kali lebih rendah untuk mengalami nyeri berat bila dibandingkan dengan bayi pada kelompok kontrol, atau dengan kata lain bayi yang diberi ASI dengan cara menyusui saat diimunisasi dapat menurunkan resiko terjadinya nyeri berat sebesar $80 \%$ dibandingkan dengan kelompok kontrol.

Tabel 3. Perbedaan Tingkat Nyeri Responden Kelompok Intervensi dan Kelompok Kontrol

\begin{tabular}{cccccc}
\hline Variabel & Kelompok & Mean $($ SD) & 95\%CI(lower-uper) & $\boldsymbol{p}$-value & $\boldsymbol{R R}$ \\
Tingkt Nyeri & Kontrol & $8,8611(1,01848)$ & $8,5165-9,2057$ & 0,000 & 0,206 \\
& Intervensi & $5,0882(1,63980)$ & $4,5161-5,6604$ & & \\
\hline
\end{tabular}

Tingkat nyeri bayi saat penyuntikan imunisasi pada penelitian ini diukur menggunakan alat ukur nyeri FLACC
(Face, Legs, Activity, Cry, Consolability). Penilaian nyeri dilakukan mulai dari "in" jarum 
disuntikkan ke bayi sampai kurang dari 1 menit pertama setelah "out" jarum dicabut dari paha bayi.

Penelitian ini membuktikan bahwa perlindungan alami dan aman dapat diperoleh dengan cara pemberian ASI melalui menyusui selama tindakan invasif. Penelitian Modarres et al., (2013) yang menyebutkan bahwa pemberian ASI dengan cara menyusui sangat efektif sebagai analgesic dalam menurunkan nyeri bayi saat mendapat imunisasi Hepatitis B $(p<0,001)$. Gray et al., (2002) menyebutkan lama tangisan dan ekspresi wajah kesakitan menurun secara signifikan sebesar $91 \%$ dan $84 \%$, dan denyut jantung bayi cenderung turun secara stabil pada kelompok yang mendapatkan ASI saat tindakan pengambilan darah tumit. ${ }^{11}$ Hal tersebut karena adanya rasa manis yang terkandung pada ASI dapat menstimulasi taktil indera perasa dimulut dan menyebabkan mekanisme pelepasan opioid endogen, yang diketahui berperan sebagai salah satu zat yang menghambat dan menutup gerbang nyeri sehingga mempengaruhi penurunan sensasi nyeri (Gray L, et al, 2002). Penelitian Okan et al., (2010) menunjukkan bahwa bayi yang mendapat ASI dengan skin-to-skin contact dari ibu saat menyusui mampu menurunkan respon nyeri secara fisiologi dan secara perilaku dibandingkan dengan skin-to-skin contact dilengan ibu tanpa diberi ASI (Okan F, et al, 2010). Penelitian Gray et al (2002) melaporkan bahwa pemberian ASI sebelum, selama, dan setelah tindakan hell prick mampu menurunkan tangisan dan ekspresi meringis, serta mencegah peningkatan denyut jantung pada bayi cukup bulan, dibandingkan dengan bayi yang hanya dibedong (Gray L, et al, 2002).

Intervensi pemberian ASI dengan cara menyususi telah terbukti dapat menurunkan resiko terjadinya nyeri berat sebesar $80 \%$ dibandingkan dengan kelompok kontrol. Kenyamanan yang dirasa bayi ditunjukkan dengan adanya perubahan tingkah laku dan penurunan skor tingkat nyeri bayi. Sebagian kecil bayi menunjukkan skor tingkat nyeri ringan (1-3) pada saat diimunisasi. Persentase nyeri ringan hanya terdapat pada responden kelompok intervensi yang mendapat ASI dengan cara disusui, sedangkan pada kelompok kontrol semua responden berada pada skor tingkat nyeri berat (7-10). 


\section{SIMPULAN}

Implementasi pemberian ASI secara menyusui terbuktif efektif dalam menurunkan respon nyeri bayi selama tindakan invasif. Variabel lain dalam penelitian ini secara keseluruhan tidak bermakna terhadap respon nyeri bayi diantaranya; umur, jenis kelamin, dan pengalaman nyeri sebelumnya baik pada kelompok intervesi maupun kelompok kontrol.

Penelitian ini dapat diterapkan dilapangan seperti Puskesmas, dan posyandu untuk memberikan pelayanan prima pada tingkat pelayanan masyarakat- Penelitian selanjutnya mengembangkan pada alternatif metode dan alat ukur terhadap respon nyeri bayi prematur pada tindakan invasif di rumahsakit.

\section{DAFTAR PUSTAKA}

Badr, L.K., Abdallah, B., Hawari, M., Sidani, S., Kassar, M., Nakad P. Determinans of Premature Infant pain Responsses to Heelsticks. Pediatr Nurs. 2010;36 (3):12936.

Carbajal R, Veerapen S, Couderc S, Jugie M, Ville Y. Analgesic Effect of Breast Feeding in Term Neonates :

Randomised Controlled Trial. BMJ. 2003;326(January).
Gradin M, Finnström O, Schollin J. Feeding and oral glucose-additive effects on pain reduction in newborns. Early Hum Dev. 2004 Apr;77(1-2):57-65.

Gray L, Miller LW, Philipp BL, Blass EM, Hospital B. Breastfeeding Is Analgesic in Healthy Newborns. 2002;109(4).

Kassab M, Almomani B, Nuseir K, Alhouary A a. Efficacy of Sucrose in Reducing Pain during Immunization among 10- to 18Month-Old Infants and Young Children: A Randomized Controlled Trial. J Pediatr Nurs [Internet]. 2020;50:e55-61. Available from: https://doi.org/10.1016/j.pedn.20 19.11.010

Modarres M, Jazayeri A, Rahnama P, Montazeri A. Breastfeeding and pain relief in full-term neonates during immunization injections : a clinical randomized trial. 2013;

Okan F, Ozdil a, Bulbul a, Yapici Z, Nuhoglu a. Analgesic effects of skin-to-skin contact and breastfeeding in procedural pain in healthy term neonates. Ann Trop Paediatr. 2010 Jan;30(2):119-28.

Pope N, Tallon M, Leslie G, Wilson S. Ask me: Children's experiences of pain explored using the draw, write, and tell method. J Spec Pediatr Nurs [Internet]. 2018 Jul;23(3):e12218. Available from: http://doi.wiley.com/10.1111/jsp n. 12218 
Potter PA, Perry AG. Fundamentals of Nursing: Concepts, Process, and Practise. 4 Vol.2. Komalasari, R., Evriyani, D., Noviestari, E., Hany, A., Kurnianingsih, S. Edt. Ester, M. Yulianti. D., Parulian I, editor. Jakarta: EGC; 2005.

Ps S, Ll A, Vs S. Breastfeeding or Breast Milk for Procedural Pain in Neonates ( Review ). Cochrane Collab. 2009;(1).

Sanz-rojo S, Garicano-vilar E. Nutrición Hospitalaria. Nutr Hosp. 2016;33(1):148-55.
Schechter NL, Zempsky WT, Cohen LL, McGrath PJ, McMurtry CM, Bright NS. Pain Reduction During Pediatric Immunizations: Evidence-Based Review and Recommendations. Pediatrics. 2007 May;119(5):e1184-98.

Sridharan K, Sivaramakrishnan G. Pharmacological interventions for reducing pain related to immunization or intramuscular injection in children: A mixed treatment comparison network meta-analysis of randomized controlled clinical trials. J Child Heal Care. 2018;22(3):393-405. 